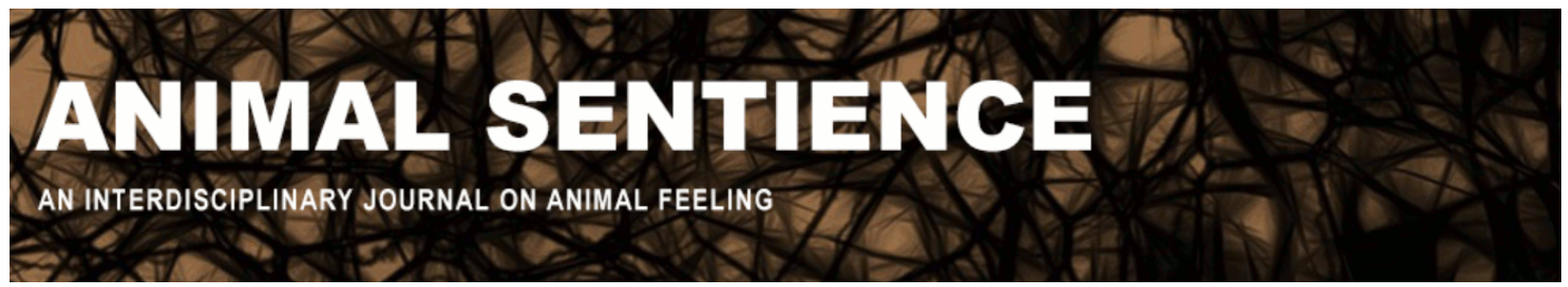

Correia Caeiro, Catia (2019) Cognitive dissonance about sheep cognition and consumption. Animal Sentience 25(39)

DOI: $10.51291 / 2377-7478.1489$

Date of submission: 2019-06-11

Date of acceptance: 2019-06-28

(c)

This article has appeared in the journal Animal

Sentience, a peer-reviewed journal on animal

cognition and feeling. It has been made open access,

free for all, by WellBeing International and deposited

in the WBI Studies Repository. For more information,

please contact

wbisr-info@wellbeingintl.org.

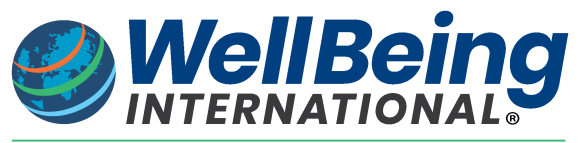

SOLUTIONS FOR PEOPLE, ANIMALS AND ENVIRONMENT 


\title{
Cognitive dissonance about sheep cognition and consumption
}

Commentary on Marino \& Merskin on Sheep Complexity

\author{
Catia Correia Caeiro \\ School of Life Sciences \\ University of Lincoln, UK
}

\begin{abstract}
Sheep are perceived as mere resources under the massive demand of the food and wool industry. Evidence that sheep cognition is comparable to that of other species may inspire reflection on sheep consumption. Dogs may be a promising comparison species.
\end{abstract}

Catia Correia Caeiro studies the cognitive capacities of different species (e.g., primates and domestic animals), applying a comparative and evolutionary perspective. Her research focuses on communication and emotional expression in animals. Website

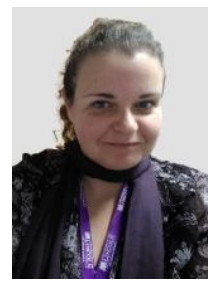

1. Sheep as a resource. Most people consider humans morally superior to other species because they believe we have superior cognitive abilities (Singer 2009; Chapman \& Huffman 2018). This speciesism, placing all other animals - domestic and wild - below humans, makes them a morally acceptable resource to exploit (Tian et al. 2016; Leroy \& Praet 2017; Franklin 2019). Sheep are not a special case; the choice of which species to domesticate and use as resources is not based on cognitive inferiority (Diamond 2002). Marino \& Merskin's (M\&M's) (2019) review induces cognitive dissonance (Leroy \& Praet 2017; Ong et al. 2016): evidence that sheep are as sentient as dogs and have cognitive skills comparable to those of horses should make us reflect on animal welfare and on using animals as mere resources.

Vegetarianism and veganism based on consumer awareness of animal welfare and environmental concerns are growing (IPSOS Mori 2018). Experts have called for a less meatbased diet to reduce the impact of human meat consumption on human, animal and planetary health (de Boer et al. 2017). Surprisingly, neither the target article nor the commentaries on it (other than D'Silva 2019) mention the topic of meat consumption. Even if sheep welfare is improved, as Horback (2019) recommends, the huge demand for meat by the exponentially growing human population will never have enough resources (e.g., space) to allow optimal welfare for all animals produced for food and other human uses.

As Baker (2019) notes, more exposure to sheep as feeling, thinking individuals might change people's minds (Morris et al. 2012). In human perception, familiarity increases attractiveness (e.g., the other-race face effect; Peskin \& Newell 2004; Zebrowitz et al. 2008). The cognitive dissonance from knowing about animal suffering can change people's attitudes (Ong et al. 2016). Empathy has been shown to correlate with meat avoidance (Rothgerber \& Mican 2014). M\&M's article will be important in convincing people that sheep are moral individuals with emotions and complex cognition. 
2. Sheep as sentient individuals. All mammals have the basic brain systems for producing and processing emotions, so there is little doubt that sheep, too, are emotional individuals. Species differences can also be important, however, and we have to be alert for anthropomorphic biases. M\&M's target article conflates facial expression discrimination and emotion recognition. These are two distinct processes; the first has clearly been shown in sheep but the latter has not yet been shown. To study emotional cues in another species, we first need to use objective methods to identify what those cues are. There is widespread misunderstanding, for example, about emotions and communicative cues in dogs, not only because humans have a default tendency to read other species as if they were humans, but also because the way other species communicate can be strikingly different (e.g., humans don't pay attention to ears whereas sheep use them as core expressive cues). To measure facial expressions in animals objectively, animal Facial Action Coding Systems (FACS, based on the widely used human FACS of Ekman 1997) have been developed for several species (e.g., Parr et al. 2007; Caeiro et al. 2013, though a sheep FACS remains to be developed). In a bottom-up approach, emotions can also be categorized according to their underlying neurobiology (Caeiro et al. 2017) rather than universal human emotions (Ekman 1992).

M\&M's classification of emotions is open to question. Basic emotions are not called "basic" because they are simple or less relevant. Basic or primary emotions are arguably the pillars of fitness and survival, allowing organisms to react appropriately to the cues in their environment. M\&M do not specify which emotions are considered basic, but they do mention Panksepp (2004), for whom fear, happiness, attachment, anticipation, frustration, etc., are basic, as supported by widely published neurobehavioral data across species. According to $M \& M$, cognitive bias, emotional reactions to learning, emotional contagion and social buffering are examples of complex or secondary emotions. This is misleading. These phenomena are not emotions per se; they are a set of behaviors and/or brain processes during which emotions are triggered and can be measured. For example, cognitive bias, found even in bees (Bateson et al. 2011; Horback 2019), occurs when information processing is changed by the positive or negative affective state of the individual (Harding et al. 2004). This is not a complex cognitive mechanism; it lacks markers of complexity such as intentionality, planning and a goalorientated action (Funke 2009). Complex emotions (e.g., contempt, jealousy) - which require some sense of self and theory of mind, and might depend on culture - have yet to be convincingly demonstrated in nonhuman animals (cf. Cook et al. 2018). This is not necessarily a negative feature in animals and in no way implies that they are less "intelligent"; it may instead be a positive feature of animal minds (Kujala et al. 2017).

3. Sheep as an intelligent species. The definition of intelligence is also problematic. Even in humans, there is no consensus on how to measure it. Nor is intelligence relevant to showing that sheep are sentient individuals with a rich Umwelt. It might be better either to avoid it completely or to take a more objective approach (Phillips 2019; Vonk 2019; Horback 2019), where intelligence is not measured in absolute terms, but is defined relative to each species' problem-solving ability within its own natural and social environments (Roth \& Dicke 2005). It is interesting to compare sheep with primates, who are phylogenetically close to humans, but we also have to take into account the important effects of domestication, which is known to modify species' cognitive abilities. Perhaps comparisons with the dog (Baker 2019; Rollin 2019) 
- one of the most successful domestic species, and increasingly well-studied - would be more effective in changing human perception of sheep. I cannot agree, however, with the commentators who suggest that we should move away altogether from comparisons with humans, arguably the best-studied species. Just about every mental phenomenon and measuring technique has been studied first in humans, hence humans can be used as a baseline to study the cognitive traits of other species.

Conclusion. Along with Vonk and other commentators, I applaud M\&M's comprehensive review of sheep cognition but would urge more objective analysis in order to inform policy. In addition, policy-makers and researchers need to take into account the fact that one of the causes of sheep suffering is that mutton is on the menu for our "superior" species. Hence uncomfortable topics such as veganism also need be discussed if the lives of sheep are to be improved. Although the pessimism of Davis (2019) is totally justifiable, I am more optimistic after reading M\&M's target article. Diets without meat, and lifestyles without animal products derived from suffering, are becoming more widely accessible commercially as consumer demand increases. Some sheep species (Valais Blacknose) are even being adopted as pets today; such a shift from food source to family membership might also help change the perception of this species.

And although M\&M do not discuss other farmed species in this target article (cf. Marino \& Colvin 2015; Marino 2017a,b), the points raised here clearly apply to them as well.

\section{References}

Baker, L. (2019). Is knowing enough to change human attitudes and actions?. Animal Sentience 25(4).

Bateson, M., Desire, S., Gartside, S. E., \& Wright, G. A. (2011). Agitated honeybees exhibit pessimistic cognitive biases. Current Biology, 21(12), 1070-1073.

Caeiro, C. C., Waller, B. M., Zimmermann, E., Burrows, A. M., \& Davila-Ross, M. (2013). OrangFACS: A muscle-based facial movement coding system for orangutans (Pongo spp.). International Journal of Primatology, 34(1), 115-129.

Caeiro, C., Guo, K., \& Mills, D. (2017). Dogs and humans respond to emotionally competent stimuli by producing different facial actions. Scientific Reports, 7(1), 15525.

Chapman, C. A., \& Huffman, M. A. (2018). Why do we want to think humans are different?. Animal Sentience 23(1).

Cook, P., Prichard, A., Spivak, M., \& Berns, G. S. (2018). Jealousy in dogs? Evidence from brain imaging. Animal Sentience 22(1).

Davis, H. (2019). Our disparaging view of sheep is indeed based on cognitive inadequacy: Unfortunately, it's ours. Animal Sentience 25(20).

de Boer, J., Schösler, H., \& Aiking, H. (2017). Towards a reduced meat diet: Mindset and motivation of young vegetarians, low, medium and high meat-eaters. Appetite, 113, 387-397.

Diamond, J. (2002). Evolution, consequences and future of plant and animal domestication. Nature, $418(6898), 700$.

D'Silva, J. (2019). Reflections on sheep rearing. Animal Sentience 25(5).

Ekman, P. (1992). An argument for basic emotions. Cognition \& Emotion, 6(3-4), 169-200.

Ekman, P. (1997). What the face reveals: Basic and applied studies of spontaneous expression using the Facial Action Coding System (FACS). Oxford University Press. 
Franklin, R. G., Jr. (2019). Why are sheep sheepish? How perception affects animal stereotyping. Animal Sentience 25(15).

Funke, J. (2010). Complex problem solving: A case for complex cognition?. Cognitive Processing, 11(2), 133-142.

Harding, E. J., Paul, E. S., \& Mendl, M. (2004). Animal behaviour: Cognitive bias and affective state. Nature, 427(6972), 312.

Horback, K. (2019). Applied cognition research to improve sheep welfare. Animal Sentience 25(18).

Kujala, M. V. (2017). Canine emotions as seen through human social cognition. Animal Sentience 14(1).

Leroy, F., \& Praet, I. (2017). Animal killing and postdomestic meat production. Journal of Agricultural and Environmental Ethics, 30(1), 67-86.

Marino, L. (2017a). The inconvenient truth about thinking chickens. Animal Sentience 17(1).

Marino, L. (2017b). Thinking chickens: A literature review of cognition, emotion, and behavior in the domestic chicken. Animal Cognition, 20(2), 127-141.

Marino, L., \& Colvin, T. (2015). Thinking pigs: A comparative review of cognition, emotion, and personality in Sus domesticus. International Journal of Comparative Psychology, 28.

Marino, L., \& Merskin, D. (2019). Intelligence, complexity, and individuality in sheep. Animal Sentience 25(1).

Morris, P., Knight, S., \& Lesley, S. (2012). Belief in animal mind: Does familiarity with animals influence beliefs about animal emotions?. Society \& Animals, 20(3), 211-224.

Ong, A. S., Frewer, L. J., \& Chan, M. Y. (2017). Cognitive dissonance in food and nutrition-A conceptual framework. Trends in Food Science \& Technology, 59, 60-69.

Panksepp, J. (2004). Affective neuroscience: The foundations of human and animal emotions. Oxford University Press.

Parr, L. A., Waller, B. M., \& Vick, S. J. (2007). New developments in understanding emotional facial signals in chimpanzees. Current Directions in Psychological Science, 16(3), 117-122.

Peskin, M., \& Newell, F. N. (2004). Familiarity breeds attraction: Effects of exposure on the attractiveness of typical and distinctive faces. Perception, 33(2), 147-157.

Phillips, C. (2019). Sacrificial lambs. Animal Sentience 25(2).

Rollin, B. (2019). Far more to sheep than meets the casual eye. Animal Sentience 25(7).

Roth, G., \& Dicke, U. (2005). Evolution of the brain and intelligence. Trends in Cognitive Sciences, 9(5), 250-257.

Rothgerber, H., \& Mican, F. (2014). Childhood pet ownership, attachment to pets, and subsequent meat avoidance. The mediating role of empathy toward animals. Appetite, 79, 11-17.

Siegrist, M., Sütterlin, B., \& Hartmann, C. (2018). Perceived naturalness and evoked disgust influence acceptance of cultured meat. Meat Science, 139, 213-219.

Singer, P. (2009). Speciesism and moral status. Metaphilosophy, 40(3-4), 567-581.

Tian, Q., Hilton, D., \& Becker, M. (2016). Confronting the meat paradox in different cultural contexts: Reactions among Chinese and French participants. Appetite, 96, 187-194.

Vonk, J. (2019). Pulling the wool from our eyes. Animal Sentience 25(3).

Zebrowitz, L. A., White, B., \& Wieneke, K. (2008). Mere exposure and racial prejudice: Exposure to otherrace faces increases liking for strangers of that race. Social Cognition, 26(3), 259-275. 